\title{
Optics in a research environment: spectroscopy as a teaching tool
}

Stephen Cobb, John Tarvin, Carol Baltimore

Stephen H. Cobb, John T. Tarvin, Carol J. Baltimore, "Optics in a research environment: spectroscopy as a teaching tool," Proc. SPIE 1603, Education in Optics, (1 March 1992); doi: 10.1117/12.57877

SPIE. Event: Education in Optics, 1991, Leningrad, Russian Federation 


\title{
Optics in a research environment: spectroscopy as a teaching tool
}

\author{
Stephen H. Cobb, John T. Tarvin, and Carol J. Baltimore \\ Department of Physics and Astronomy \\ Murray state University \\ Murray, Kentucky 42071
}

\begin{abstract}
A near-infrared reflectance spectrophotometer has been constructed and operated by a group of students with an interest in applied optics. The instrument was created by repairing and modifying a 25 year-old inoperative Cary 14 scanning spectrophotometer. Details of the modification are discussed. Students learn fundamentals of diffuse reflectance measurement, synchronous detection techniques, the use of optical instrumentation, and the physical origin of spectral features. The instrument is presently being used to measure the protein content of agricultural feeds, giving students the opportunity to develop calibration software for data analysis. Additional applications are discussed. Involved students range from college freshmen to graduate students. They, and the surrounding agricultural community, are being educated to the advantages of optical techniques as a method of nondestructive evaluation.
\end{abstract}

\section{INTRODUCTION}

The application of optical principles in non-destructive diagnostic procedures has grown in recent years. Today, optics has found an accepted place in the fields of medicine, construction, and communications, to name a few, and new applications are discovered, developed, and implemented every year. Recently, the field of agriculture has embraced the use of optics and image analysis for the inspection and quality control of its products. A major area of agricultural research brought on by advances in near-infrared technology is that of near-infrared reflectance spectroscopy (NIRS). NIRS provides a quick, reliable determination of the composition and nutrient content of agricultural products. 1 since its introduction nearly two decades ago, the NIRS method has been used to predict the protein, vitamin, mineral, and moisture content in grasses, grains, fruits, and vegetables. Interest in this and other new optics applicatjons resulted in an SPIE conference on optics in agriculture in 1990.2

The Kentucky Department of Agriculture has introduced a program stressing the importance of high quality hay production. 3 Hay which has been tested and certified to contain top nutritional value is in great demand for the feeding of thoroughbred horses and dairy and beef cattle. In order to participate in this program, and in an effort to improve the overall quality of animal feeds, farmers submit samples of hay and other forages to be examined chemically so that their 
nutritional characteristics may be evaluated. 4 This chemical analysis is generally slow and expensive. NIRS has been adopted as an inexpensive, non-destructive method which expedites the evaluation of nutritional constituents in a sample.

As there are very few NIRS instruments in the state, a group at MSU with interest in applied optics has attempted to construct and operate such a spectrophotometer. Four students are presently involved, ranging in experience from first semester freshmen to a graduate student completing the M.S. in physics. This research project has been attractive to the students because it represents the application of optical principles and instrumentation to the solution of a problem that is viewed as important in our locale. The project is significant in that it incorporates several disciplines along with optics. Physicists can appreciate the spectroscopy involved. The data handling is a challenge for those interested in computer-aided data analysis and statistics. The instrumentation and interfacing of electronics give valuable experience to those interested in hardware, and the agriculturalist's expertise is useful in interpreting the results of these measurements.

\section{THE NIRS METHOD}

NIRS is an instrumental method for quickly and reliably predicting the chemical composition of a sample. It is based on the fact that each of the major chemical components in a sample has near-infrared absorption properties which can be used to differentiate one component from another. 1 with this method, solid samples are dried, ground, and placed in front of a near-infrared light source. The diffuse reflectance is measured as a function of wavelength and this data is recorded. Proper computational treatment of the data is then necessary to extract information as to the concentration of individual constituents in the sample. NIRS spectroscopy differs from conventional infrared single band spectroscopy where individual peaks can be associated with particular stretches or vibrations of molecular bonds. In the near infrared region, the broad spectral features arise from harmonic overtones and combinations of fundamental frequencies at longer wavelengths. Single band assignment is difficult if not impossible, and correlation techniques relating concentrations of various constituents to spectral intensity at particular wavelengths is required.

\section{CONSTRUCTION OF THE NIRS INSTRUMENT}

The instrument used in the analysis must be able to detect small changes in reflectance over the wavelengths of interest and must also show good wavelength reproducibility. Our group had access to a Cary 14 spectrophotometer which had been out of service for several years and was in a state of disrepair. It was known that some of the earliest NIRS instruments were actually modified commercial spectrophotometers ${ }^{5}$, and it seemed logical to use this machine as the basis for our NIRS instrument.

The Cary 14 scanning spectrophotometer is a prism-grating double monochromator instrument manufactured in 1967. The dual-beam system 
allows for reflectance, transmittance, and absorbance measurements to be conducted at wavelengths ranging from $200 \mathrm{~nm}$ to 2.65 microns at selected speeds between 0.05 and $50 \mathrm{~nm} / \mathrm{sec}$. The measured spectra is recorded on an attached strip chart recorder with a wide choice of chart speeds and amplitude scaling. In our application, only the scanning monochromator from the original Cary instrument was retained.

In the original near-infrared measurement mode, the cary brings light from an infrared source and splits it into two beams via an optical chopper at $30 \mathrm{~Hz}$. Light from each beam alternates in passing through the double monochromator, where it is received by a $\mathrm{PbS}$ detection cell.

A block diagram of the modified spectrophotometer is presented in Figure 1. The original 18A, $6 \mathrm{~V}$ tungsten filament lamp and housing unit was replaced with a 120V, 1000W quartz tungsten halogen lamp (Oriel 6315). This lamp served as the infrared source, with its spectral irradiance peaking at about 1 micron. A quartz lens was used to focus light onto the entrance aperture of the monochromator, and a rear reflector was placed behind the source to increase the amount of light through the instrument. The original chopper was disengaged, resulting in single beam operation in the spectrophotometer. This chopper was replaced by a mechanical chopper (stanford Research Systems SR540) operating at $1000 \mathrm{~Hz}$ which allowed synchronous detection of the light through the system and gave maximum detectivity from the detection system whose description follows.

The detection geometry was altered significantly. The $\mathrm{PbS}$ detector and housing was removed from the instrument and replaced with an integrating sphere apparatus to measure diffuse reflectance. The four-inch diameter aluminum sphere (Labsphere) was coated internally with spectralon UV-VIS-NIR calibrated reflectance coating. As shown in Figure 2, light enters the sphere through a one-inch diameter entrance port. The light falls incident on the one-inch sample port directly across the sphere from the entrance port. Reflected light in the full hemisphere in front of the sample is trapped in the sphere and detected by a PbSe detector placed at 90 degrees to the incident beam and protected from specular reflectance by a baffle. The PbSe detector (IR Industries, Model 5700) is a two-stage, thermoelectrically cooled photoconductor with typical response in the 1 to 5 micron spectral range.

All modifications performed on the original instrument are easily reversed, allowing the cary to be used in its intended fashion without loss of capability.

\section{SAMPLE PREPARATION AND REFLECTANCE MEASUREMENT}

Preparation and measurement of the samples is well documented and will be discussed here only briefly. 6 It seems that there is great latitude in the details of the procedure used, with consistency being critical to the success of the method in accurately analyzing a sample. Samples of alfalfa hay were collected from local farms throughout the MSU service region. These samples were cored from baled hay lots that had been grown and stored under a variety of conditions. Effort was made to get a representative sampling of alfalfa grown in the area. These samples were dried in a microwave 
oven for 2 to 3 minutes, checking sample weight every 30 seconds to monitor the amount of moisture driven from the sample and to prevent the charring of the sample by excessive microwaving. Samples were dried to approximately 95 percent dry matter. The hay samples were then ground in a wiley mill fitted with a $1 \mathrm{~mm}$ screen sieve to assure uniform particle sizing and then stored in zip-lock pouches until ready to be scanned on the spectrophotometer.

To acquire reflectance data on the hay, 1-2 grams of hay was loaded into a plastic cylinder 2 inches in diameter by $1 / 2$ inch thick. The front of the cylinder is a window of quartz glass approximately 0.05 inches in thickness. After the hay was well packed into the cylinder, a cardboard backing disk was press-fit into place to hold the powdered hay stationary. This sample was placed at the sample port on the integrating sphere, and the monochromator scan is initiated over wavelengths from 2.0 to 1.0 microns at a rate of $25 \mathrm{~nm} / \mathrm{sec}$. The $\mathrm{PbSe}$ detector output was passed to a preamplifier (IR Industries 2500) and on to a lock-in amplifier (Stanford Research SR570) set to detect signals in synch with the $1000 \mathrm{~Hz}$ chopper. The output signal from the lock-in was passed to an IBM PC-AT compatible computer via an analog to digital interface board (IBM DAC Adapter). Readings were recorded every $0.1 \mathrm{~nm}$ during the 400 second scan. This rate of data acquisition is excessive, and recording data at every nanometer is sufficient. Similar scans were recorded with no sample present as a detector background signal measurement, and also with a known reflectance standard present to provide a calibration for reflectance values. The background signal was subtracted from all measurements, and the sample values were ratioed against the readings given by the standard, then multiplied by the known percent reflectance of the standard at each wavelength to give a value for the reflectance of the sample versus wavelength. The data is typically displayed as in Figure 3, showing log(1/Reflectance) vs. wavelength.

\section{CALIBRATION AND DEVELOPMENT OF PREDICTION EQUATIONS}

In order to calibrate the newly constructed NIRS instrument, samples with known amounts of the constituent of interest (in this case protein) must be scanned. Therefore each sample scanned on the new instrument was also scanned on a commercial, calibrated instrument (Pacific Scientific 4250) at the state Department of Agriculture office. The percent protein of each sample measured on the calibrated machine is then used to generate a set of equations of the form:

$$
\begin{aligned}
& P_{1}=C_{0}+C_{1} A_{11}+C_{2} A_{21}+\ldots+C_{n} A_{n 1} \\
& P_{2}=c_{0}+C_{1} A_{12}+c_{2} A_{22}+\ldots+c_{n} A_{n 2} \\
& \text { - } \\
& \text { • } \\
& P_{m}=c_{0}+C_{1} A_{1 m}+C_{2} A_{2 m}+\ldots+C_{n} A_{n m}
\end{aligned}
$$


where the P's are the percent protein in $m$ total samples, the $A^{\prime} s$ are usually in the form of "absorbances" or $\log 1 / R$ values at each of the $\mathrm{n}$ wavelengths, and the C's are coefficients to be determined by multiple linear regression computations. Selection of the "best" several wavelengths is made by using a forward stepwise algorithm. The computer takes the reflectance value for each sample at a given wavelength and calculates a correlation coefficient for the protein content versus the $\log 1 / R$ value. This wavelength is used along with a second wavelength, and so on, until a sufficient number of wavelengths are chosen and the residual sum of the squares in minimized. Researchers have suggested that a minimum of 10 samples be scanned for each term in the calibration equation. Our initial effort has involved the scanning of 24 samples, and we will attempt to have a three term regression equation when software development is complete.

\section{RESULTS}

In order to assess the preliminary results of our efforts, we have selected five wavelengths at which to compile reflectance data and generate a prediction equation based on the reflectance values. The wavelengths chosen represent several which have been deemed advantageous by a consensus of the research literature.5,7,8 The selected wavelengths, correlation data, and prediction equation coefficients are summarized in Table 1.

\section{SUMMARY}

The NIRS technique shows promise as a method of non-destructive evaluation of protein content in forages. The technique has also been successfully employed in other areas, including pharmaceutical analysis, measurement of sugąr content in cereals, textile research, and polymer characterization.

The construction and operation of the NIRS instrument has afforded undergraduate and graduate students an opportunity to apply the principles of optics and optical instrumentation toward the solution of a problem of considerable interest to the scientific and local communities. The students involved in this project are immersed in a multidisciplinary approach to applied science, which ultimately leads to a more complete and satisfying understanding of their particular field of study. Another important aspect of the project is that this research educates the public to the advantages of using optical techniques as a means of non-destructive evaluation. Building a healthy, trusting relationship with the public is an important step in gaining support for future applications of optics in the home and the workplace.

\section{ACKNOWLEDGMENTS}

We are grateful to Mr. Bill Rudy and the staff of the Paducah office, Kentucky Department of Agriculture, for use of the Pacific Scientific NIRS instrument. This work was supported by Murray state University CISR grant 2-12724. 


\section{REFERENCES}

1. K.H.Norris, "Definition of NIRS Analysis", Near Infrared Reflectance Spectroscopy (NIRS): Analysis of Forage Quality, G.C.Marten, J.S.Shenk, and F.E.Barton, Eds., p.6, Agricultural Research Service Handbook No. 643, USDA, Washington, D.C., 1985.

2. Proceedings of the Conference on optics in Agriculture, J.A.DeShazer and G.E.Meyer, Eds., SPIE Vol. 1379, Boston, MA, 7-8 Nov., 1990.

3. Program of the Ninth Annual Kentucky Alfalfa Conference, Kentucky Dept. of Agriculture, Frankfort, KY, February 21, 1989 .

4. A.E.Cullison, Feeds and Feeding, pp. 12-27, Reston Publishing Co., Reston, VA, 1979.

5. K.H.Norris, "NIRS Instrumentation", Near Infrared Reflectance Spectroscopy (NIRS): Analysis of Forage Quality, G.C.Marten, J.S.Shenk, and F.E.Barton, Eds., pp.12-16, Agricultural Research Service Handbook No. 643, USDA, Washington, D.C., 1985.

6. S.M.Abrams, "Sampling", "Sample preparation", and "Sample Handling", Near Infrared Reflectance spectroscopy (NIRS): Analysis of Forage Quality, G.C.Marten, J.S.Shenk, and F.E. Barton, Eds., pp.22-24, Agricultural Research Service Handbook No. 643, USDA, Washington, D.C., 1985.

7. J.S.Shenk, M.O.Westerhaus, and M.R.Hoover, "Analysis of Forages by Infrared Reflectance", J. Dairy Sci. 62, 807-812, 1979.

8. G.C.Marten, J.L.Halgerson, and J.H.Cherney, "Quality Prediction of Small Grain Forages by Near Infrared Reflectance Spectroscopy", Crop Sci. 23, 94-96, 1983.

9. E.W.Ciurczak, "Near-Infrared Spectroscopy: What it is and what it is not", Spectroscopy, Vol. 4, No. 2, pp. 14-16, 1989. 


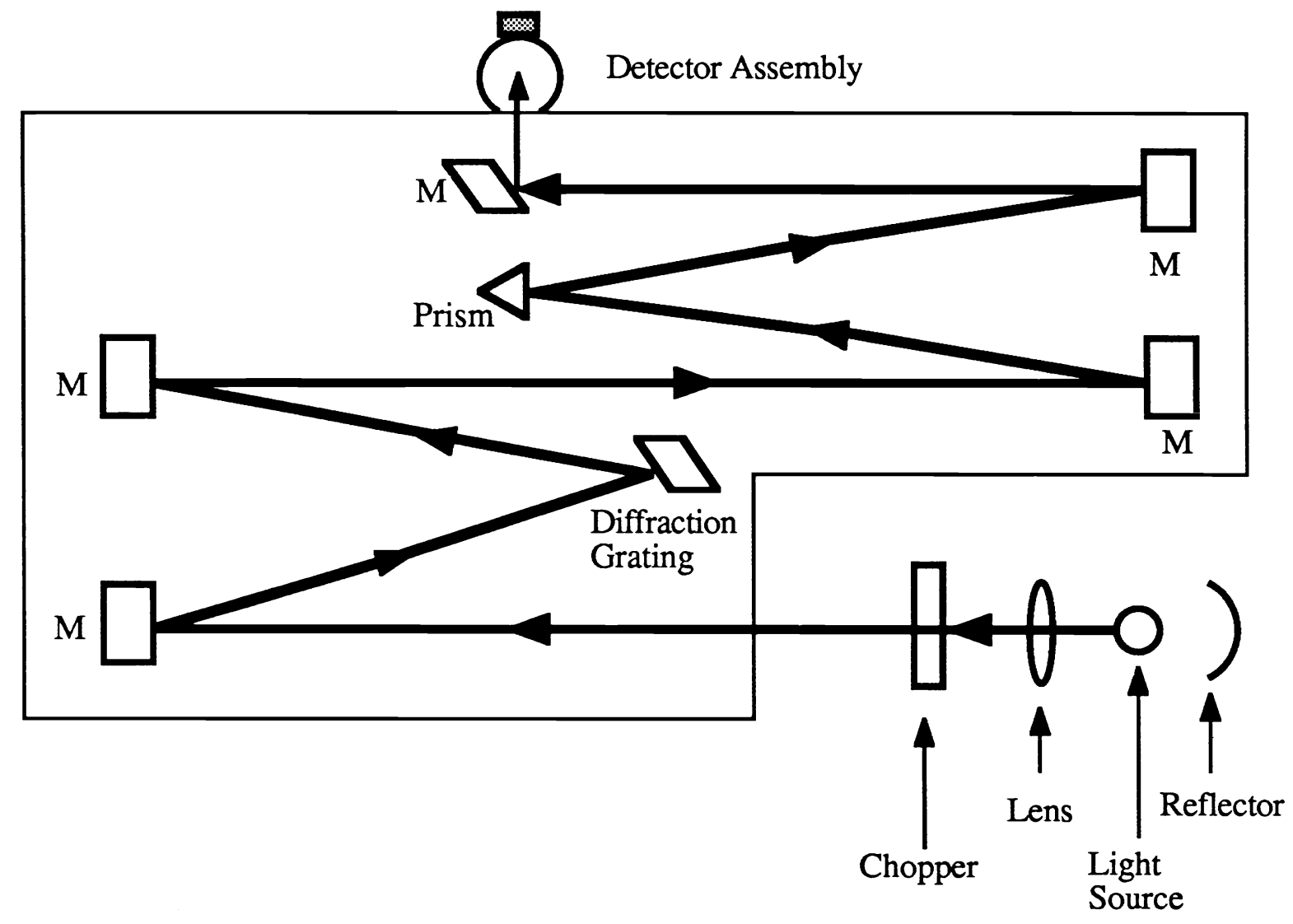

Figure 1. Schematic of the modified Cary 14 near-infrared reflectance spectrophotometer.

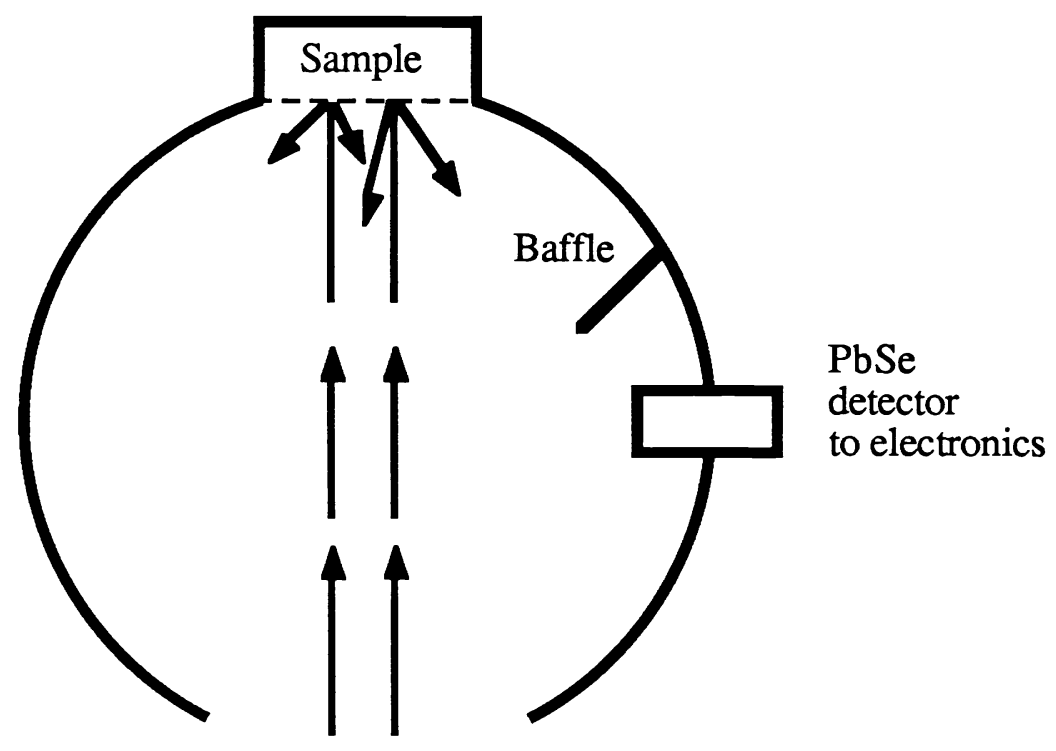

Figure 2. Integrating sphere detector assembly. 


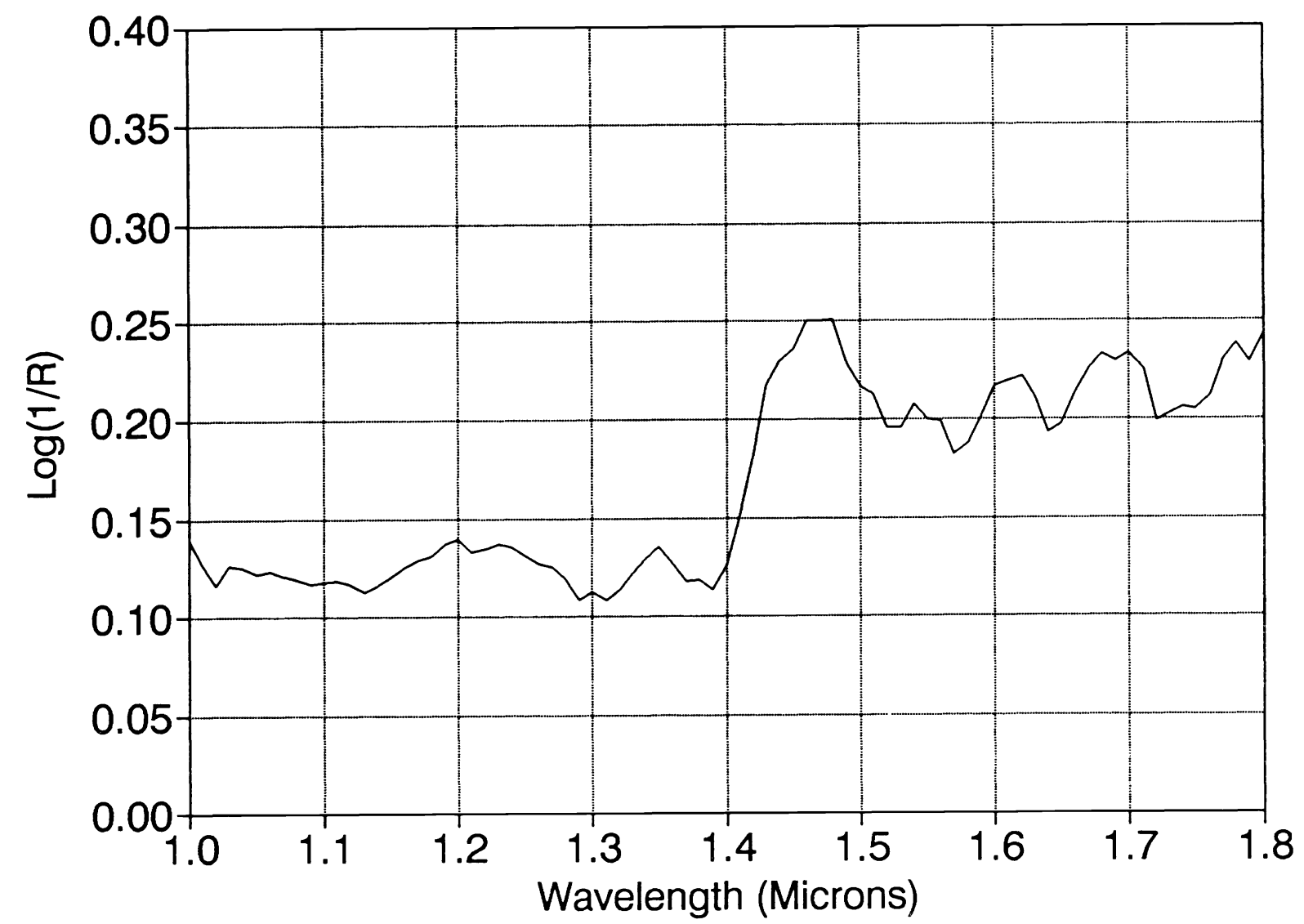

Figure 3. $\log (1 / R)$ Spectrum of Alfalfa

Table 1.Regression data for the development of a prediction equation for protein content of alfalfa using five fixed wavelengths.

Constituent $\quad \underline{R}^{2^{*}} \quad$ Math Treatment $\quad$ Wavelength $(\mu \mathrm{m})$ Prediction Coefficients**

$\begin{array}{llll}\text { Crude Protein } & 0.95 & \log (1 / \mathrm{R}) & \mathrm{C}_{0}=30.73\end{array}$

$1.270 \quad \mathrm{C}_{1}=-49.87$

$1.820 \quad \mathrm{C}_{2}=56.47$

$1.940 \quad \mathrm{C}_{3}=-70.57$

$2.100 \quad \mathrm{C}_{4}=30.13$

$2.180 \quad \mathrm{C}_{5}=-22.81$

* Coefficient of multiple determination derived from multiple linear regression analysis -

$* * \%$ Protein $=C_{0}+C_{1} A_{1}+C_{2} A_{2}+\ldots+C_{5} A_{5}$ where $A_{n}$ is the $\log (1 / R)$ at wavelength $n$ 